\section{Zuzana Mitalova \\ Darina Duplakova ${ }^{1}$ \\ Dusan Mital \\ Juliana Litecka \\ Velimir Dedic \\ Enes Sukic}

Article info:

Received 12.03.2020

Accepted 19.06.2020

UDC - 621.9.01

DOI - 10.24874/IJQR14.03-11

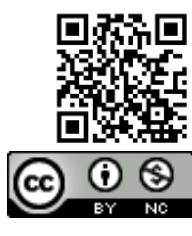

\title{
MONITORING OF SURFACE INTEGRITY OF WPC MATERIALS BASE ON EVALUATION SELECTED SURFACE TOPOGRAPHY PARAMETERS
}

\begin{abstract}
Wood-plastic composites present the specific group of composite materials consisting of plastic matrix and natural reinforcement in meal or fibre form. There are publications which are presented in the scientific databases whose field of investigating is the mechanical and physical properties, the way of manufacturing and chemical composition of WPC materials. However, there is only a small percentage in the field of machining of composite materials with the natural reinforcement. The presented article is focused on the surface topography evaluation of wood plastic composite materials after turning. Parameters of surface roughness were evaluated using the optical contactless method - MicroProf FRT optical profilometer. During the turning process, a trace is formed on the surface profile - in the form of thread with the expected pitch. Surface roughness parameters and conclusions were formulated according to obtained results.
\end{abstract}

Keywords: Surface integrity; Machining; Wood Plastic Component

\section{Introduction}

There is an evident need for lifetime increase regarding the conventional renewable materials. Wood products made in our geographical latitudes are not sufficiently resistant on humidity or biological environment, which have the major influence on their life durability. Without proper maintenance, those materials are degrading in a short time. One option is to replace the wood products with WPC composite materials. One of the advantages of WPC materials is that the extrusion process can provide a precise profile possibility. However, in some applications, there is a necessity to use conventional technologies (interaction of tool and material) for the creation of machined surface. There are defined factors which significantly influence surface after machining and impact on properties, known as technological parameters. (Hatala et al. 2019; Zelinka et al., 2019; Panda et al., 2017; Duplak et al., 2017) Through the evaluation of these characteristic surface properties are described and its quality - topography. Generally, the machinability of WPC materials is reported as to be "good". However, the number of studies presented in this area is relatively at low level, which is also reflected in the graphical representation, Figure 1.

The first reports from the field of WPC material machining are oriented on the application of PCD material tools during the conventional machining (polycrystalline diamond: application in the machining of $\mathrm{Cu}$, $\mathrm{Al}$, composite materials with glass fibres and plastics with carbon or natural fibres) (Waltz, 1982).

\footnotetext{
${ }^{1}$ Corresponding author: Darina Duplakova Email: darina.duplakova@tuke.sk
} 


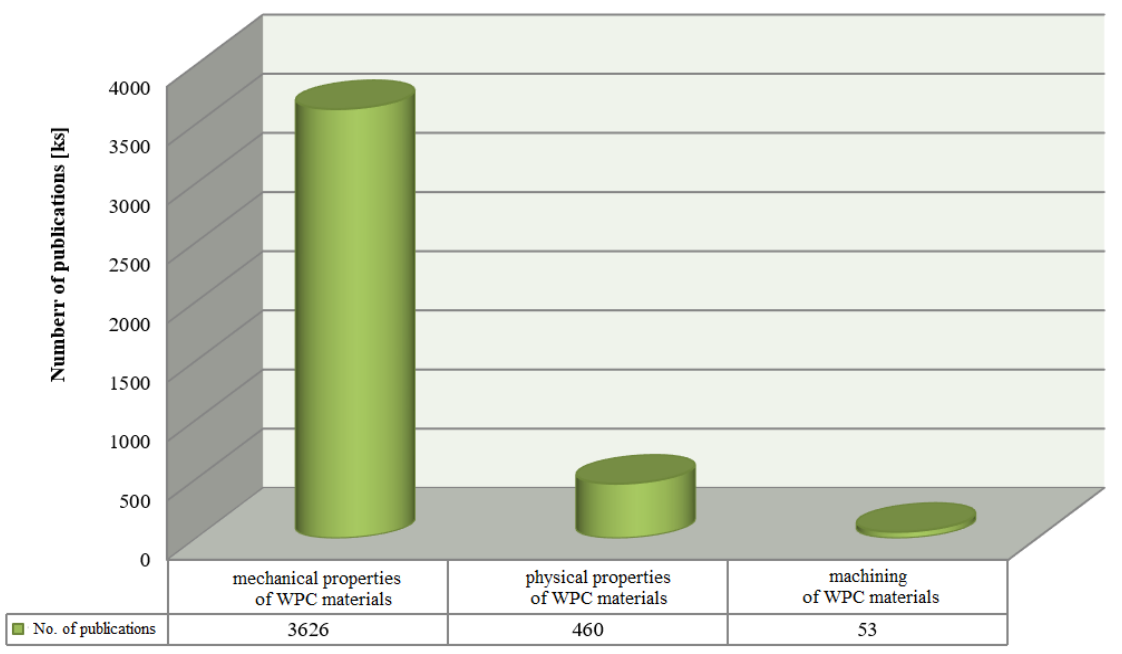

Figure 1. Ratio of publications to the related research areas

From Figure 1, it is evident that the significant interest of the research community arose in the field of WPC material machining after 2000 (Figure 2). North Carolina State University's Wood Machining and Tooling Program took patronage of research by authors (Buehlmann et al., 2014). This research was focused on carbide tool wear testing and machined surface quality evaluation of WPC materials for commercial use in floor industry after the milling and grinding process. In the machining process the Sandvik H3F cutting tool was used (3\% Co, $97 \%$ tungsten carbide - high wear resistance and medium resistance of corrosion). The result is as follows:
"Evaluation of roughness after grinding operation was realized for all samples, and also for reference sample made of homogeneous wood." After that, grinding belt wear was analysed, and the comparative specimen was determined the hard maple wood. The life span of the belt during the machining of materials was the following: CHOICEDEK - 40 min, FIBERON - 150 min, SMARTDECK - 40 min, TREX - 31 min, JAVOR - 54 min. Selected composite materials vary in composition and manufacturer. Only one value - $150 \mathrm{~min}$ stands out from the recorded values, which is a significant advantage of this composite material over other. (Buehlmann et al., 2014)

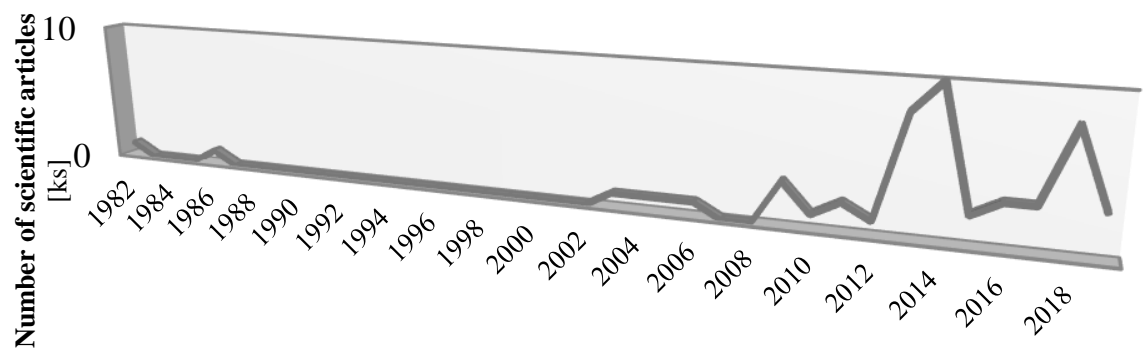

Figure 2. Number of scientific articles from 1982 up to the present (source: Scopus database, keywords: machining of wood plastic composite) 
Surface topography quality after machining and grinding was described by authors from Nanjing Foresty University in China. In their research, there was compared 2D characteristics of three different machined biomaterial surfaces (PP matrix + meal filler from rise skin, $\mathrm{PE}+$ meal filler from rise skin, PVC + meal filler from rise skin). As the grinding belt speed increases, the values of $\mathrm{Ra}, \mathrm{Rz}, \mathrm{Rk}$ decrease (average values of $\mathrm{Ra}$ parameter $<6 \mu \mathrm{m}$ ), (Guo et al., 2010).

Research by Polish authors is focused on machinability index creation of WPC materials. This research compares machinability index of three types of WPC materials (reinforcement - pine wood particles + PE / PP / PS matrix) with two commercial boards (MDF - Medium Density Fiberboard, PB - Particle Board). At the end of this article, there is a confirmation that WPC machinability indexes are similar than MDF machinability indexes. (Wilkowski et al., 2013)

The consequent work is dealing with the technology of turning WPC materials and topography of the resulting surface (specifically parameters $\mathrm{Ra}, \mathrm{Rz}$ during the machining with HSS monolithic turning tools). Parameters of surface integrity $\mathrm{Ra}$ were realized in 3 separate points on the turning surface, and there were fundamental differences between them. The work concludes that one of the fundamental problems of this material is its inhomogeneity (imperfect encapsulation of wooden particles with plastic). (Somsakova et al., 2012; Hutyrova et al. 2016)

Similarly, water jet technology (WJ / AWJ Water Jet, Abrasive Water Jet - Fig. 3) was applied in WPC machining. During the study of the influence of process factors on the quality of machined surface - two parameters were nominal:

- $\mathrm{AWJ} / \mathrm{WJ}$ feed rate $(20,30,40,50$, $60 \mathrm{~mm} \cdot \mathrm{min}^{-1}$ )

- the size of the MESH abrasive particles used (80/120, respectively without abrasive applied).
Spindle speed and abrasive mass flow constant $\left(n=34 \mathrm{rpm}, \mathrm{m}_{\mathrm{A}}=400 \mathrm{~g} \cdot \mathrm{min}^{-1}\right)$.

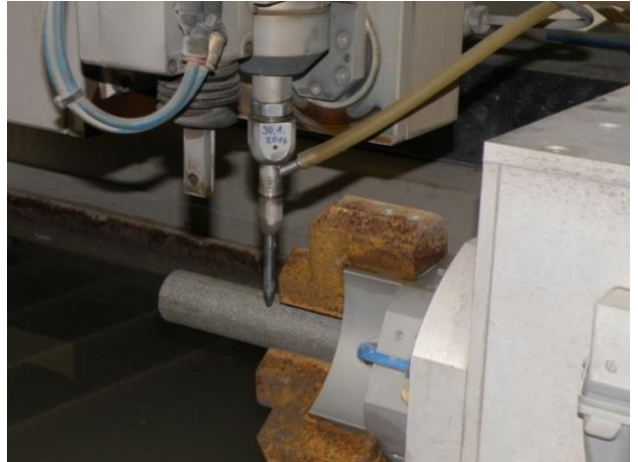

Figure 3. WPC sample in the clamps -

AWJ/WJ turning (Hutyrova et al., 2016)

Basic parameters of surface roughness were determined by MicroProf FRT optical profilometer in accordance with ISO 4287 standard. Using AWJ technology by eliminating the tool wear is possible (in the sense of melting and gluing the plastic matrix to the functional surfaces of the used tool). The resulting surfaces have the shape of a thread with different shapes and dimensions, and the best surface is produced at lower feed rates using an abrasive. At higher feed rates, the surface is roughened (Fig. 4). As with chip machining, the quality is influenced by the different mechanical characterization of initial particles of the composite material wood/plastic. The surface is damaged in places by partial cleavage of wooden particles from the plastic matrix.

A lot of articles were published dealing with milling technologies, in which the authors evaluate the shapes of the chip produced (but the work does not mention the conditions of the cutting process and tool geometry, only images of the chips are marked as "suitable not suitable"), and surface quality after milling (depending on changing process parameters). The quality of the machined surface depends not only on the cutting process conditions but also on the tool geometry and temperature in the cutting zone. (Wei et al., 2016; Wei et al., 2018) 


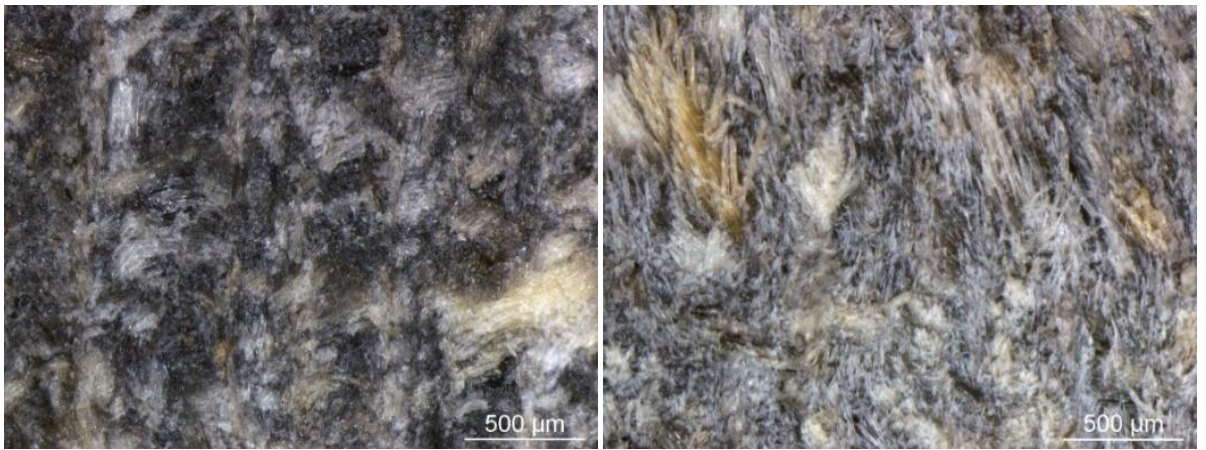

Figure 4. Surface of the sample after the AWJ turning (minimum rate of travel) with use 80 MESH abrasive (left), the surface downy appearance of the turning sample without abrasive (the same rate of travel) (right) (Hutyrova et al., 2016)

The International Wood Products Journal has published a detailed publication on the wear of coating cutting tools when machining multiple types of materials - including WPC (types of tools used - non-coated carbide tool, TiAlN coated carbide tool, TiAlN / TiSiN coated carbide tool, TiAlN / TiBN coated carbide tool). Regarding the wear, the authors consider the last-mentioned - carbide tool coated with TiAlN / TiBON (multilayer coating applied to a monolithic carbide tool Table 1) as the most suitable. Similarly, they evaluated the surface quality on the basis of the mean arithmetic deviation of the assessed profile - $\mathrm{Ra}[\mu \mathrm{m}]$, where the reported values did not exceed $5000 \mathrm{~mm}$ (when applying all four tools). (Pagestu et al., 2018)

Table 1. Wear mechanism of coated carbide cutting tool (TiAlN/TiBON multilayer coating) (Pagestu et al., 2018)

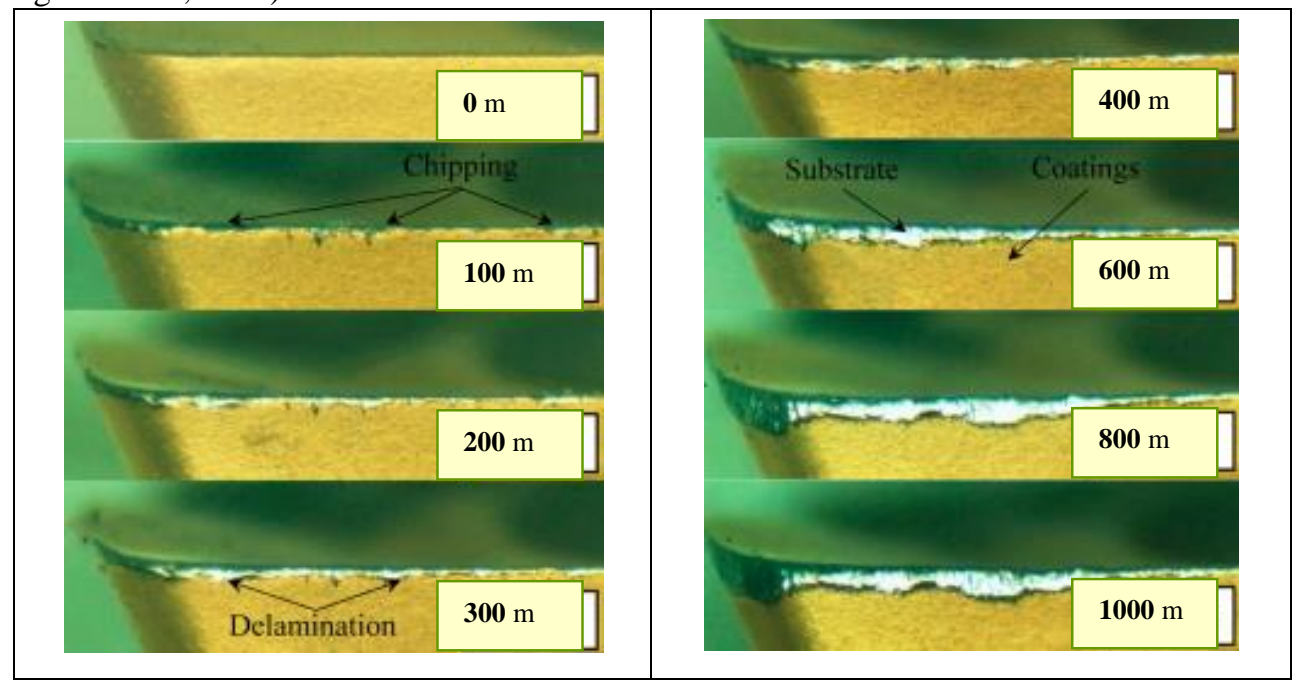

The aim of this article is to supplement the surface topography information of WPC plastic samples after turning as one of the indicators of technological inheritance (by application of contactless profilometry). 


\section{Material and methods}

Samples of WPC material (beam with dimensions: $40 \times 60 \times 3600 \mathrm{~mm}$ ) consisting of an HDPE matrix reinforced with wood fibres (chips at a ratio of $25 / 75$ vol. $\%$ ) were used in the experiment. The wood particle guide follows the polymer flow in the extrusion technology. The particles are fully or partially supersaturated with plastic (flow of wood particles - directed in the direction of movement of the extruded mass).

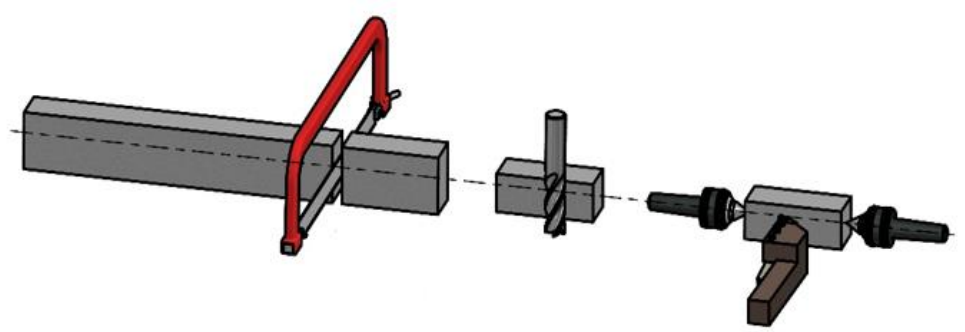

Figure 5. Sequence of steps before the final turning

Before turning, the samples were divided into $0.15 \mathrm{~m}$ length. Ergonomic 275.230 frame saw was used - step 1 . Subsequently it milled to a square section of $40 \times 40 \mathrm{~mm}$ dimensions. It was used $\mathrm{CNC} 3$-axis Pinnacle machine VMC650S - step 2. From a square crosssection, the samples were turned to a diameter of $36 \mathrm{~mm}$ (with a conventional SUI 40 lathe, a conventional chuck was used to ensure workpiece rotation - step 3), with the front faces aligned. Final turning to diameter $d$ was performed at a cutting depth $\mathrm{a}_{\mathrm{p}}=25.10^{-1} \mathrm{~mm}$ (step 4). Steps 1-3 are presented in Figure 5. During the experiment, there were measured two parameters - feed and spindle speed. Marking of samples based on abovementioned parameters is presented in Table 2 .
Table 2. Identification of samples according to parameters

\begin{tabular}{|c|c|c|}
\hline $\begin{array}{c}\text { Sample } \\
\text { identification }\end{array}$ & $\begin{array}{c}\text { Feed } \\
{[\mathrm{mm}]}\end{array}$ & $\begin{array}{c}\text { Spindle speed } \\
{\left[\text { ot. }^{-1}\right]}\end{array}$ \\
\hline $\mathrm{X} 1$ & $1.10^{-1}$ & 7.5 \\
\hline $\mathrm{X} 5$ & $61.10^{-2}$ & 7.5 \\
\hline $\mathrm{X} 6$ & $1.10^{-1}$ & 15 \\
\hline $\mathrm{X} 10$ & $61.10^{-1}$ & 15 \\
\hline $\mathrm{X} 11$ & $1.10^{-1}$ & 23.3 \\
\hline $\mathrm{X} 15$ & $61.10^{-2}$ & 23.3 \\
\hline
\end{tabular}

Analysis of surface topography of turned samples was realised by MicroProfFRT profilometer. The technical specification is presented in the following table. Analysis of obtained data was realised by Gwyddion freeware software.

Table 3. Basic parameters of MicroProf FRT optical profilometer

\begin{tabular}{|l|c|}
\hline Range (minimum) $[\mu \mathrm{m}]$ & $200 \times 200$ \\
\hline Measuring range $\mathrm{z}$ & from $300 \mu \mathrm{m}$ to $3 \mathrm{~mm}$ \\
\hline Resolution (vertical) $[\mu \mathrm{m}]$ & 0.003 \\
\hline Resolution (lateral) $[\mu \mathrm{m}]$ & 2 \\
\hline $\begin{array}{l}\text { The rake angle of surface roughness to middle plane } \\
\text { of the area }\end{array}$ & $30^{\circ}$ \\
\hline
\end{tabular}

Three dimensional profiles were obtained by monitoring horizontal and vertical axes with dimension $400 \times 400$ lines per sample and spacing was set to $0.005 \mathrm{~mm}$. Figure 6 describes three result 3D Profile obtained from software for sample X1 where the surface texture can be seen (colour scaling of the image is illustrative, a curvature is visible on the surface since it is a cylindrical surface - a turned sample). 

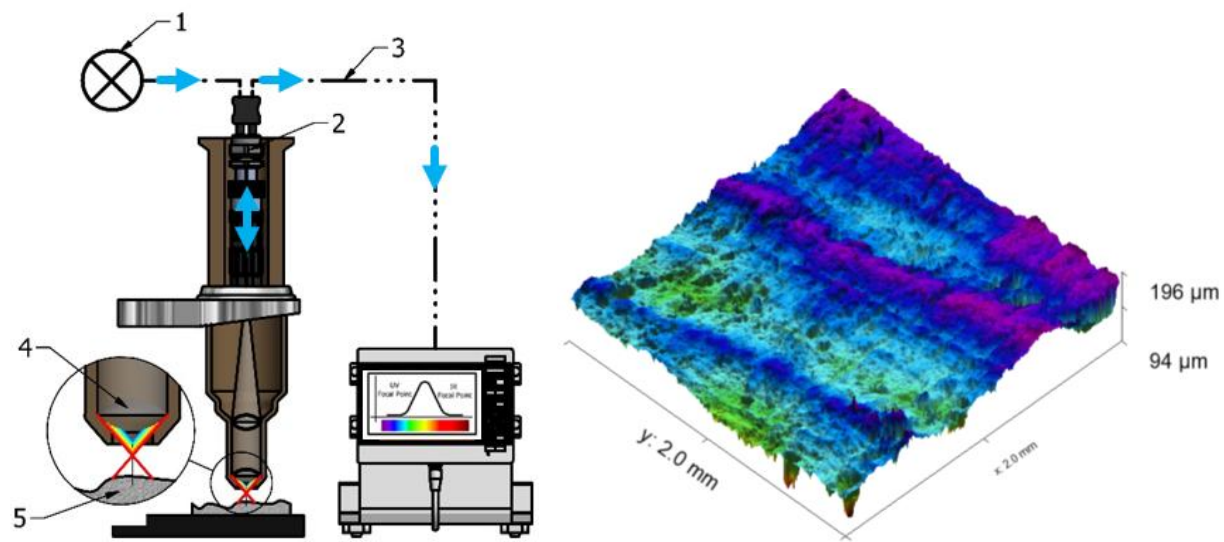

Figure 6. MicroPorf FRT 1 - light source, 2 - interface, 3 - optical cable, 4 - a lens with hight chromatic aberration, 5 - investigated suraface (left) (Valiček et al., 2015),

3D surface topography (right)

\section{Results and discussion}

From the scanned areas on the surface of each sample, sample X1 was selected for more detailed analysis (Fig. 7). Before the evaluation, the following steps had to be taken in Gwyddion:

- leveling the scanned surface,
- enhanced image colour (for better legibility when measuring bandwidth)

- $\quad$ rotating the scanned area at an angle;

- sketched lines and readings of surface roughness parameters $\mathrm{Ra} /$ Rz.

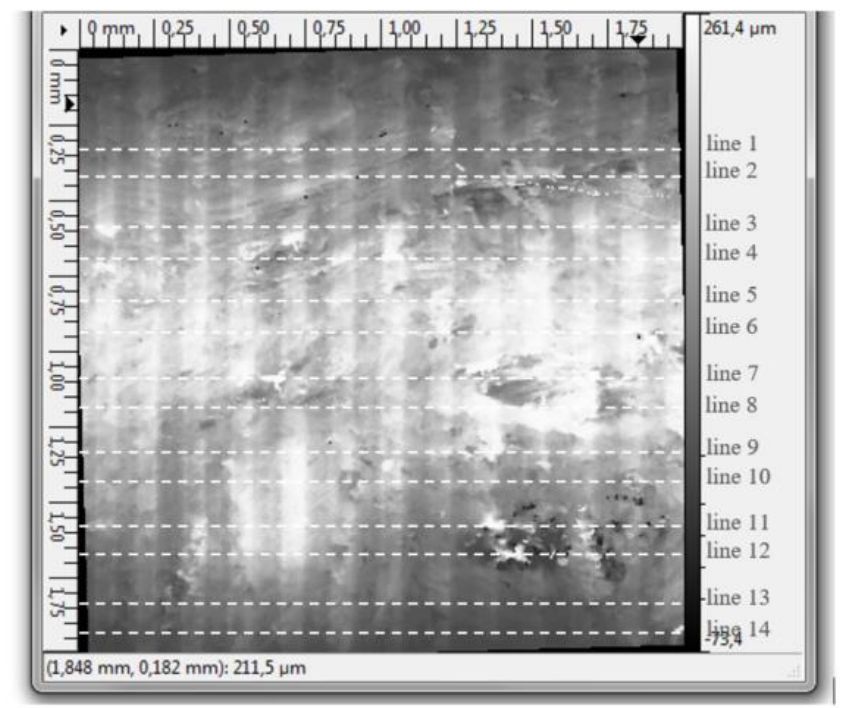

Figure 7. Scanned area (size: $2 \times 2 \mathrm{~mm}$ )

According to ISO 4287, the surface roughness parameters ( $\mathrm{Ra}$ and $\mathrm{Rz}$ ) were evaluated on the scanned surface lines Figure 8 and Figure 9. 


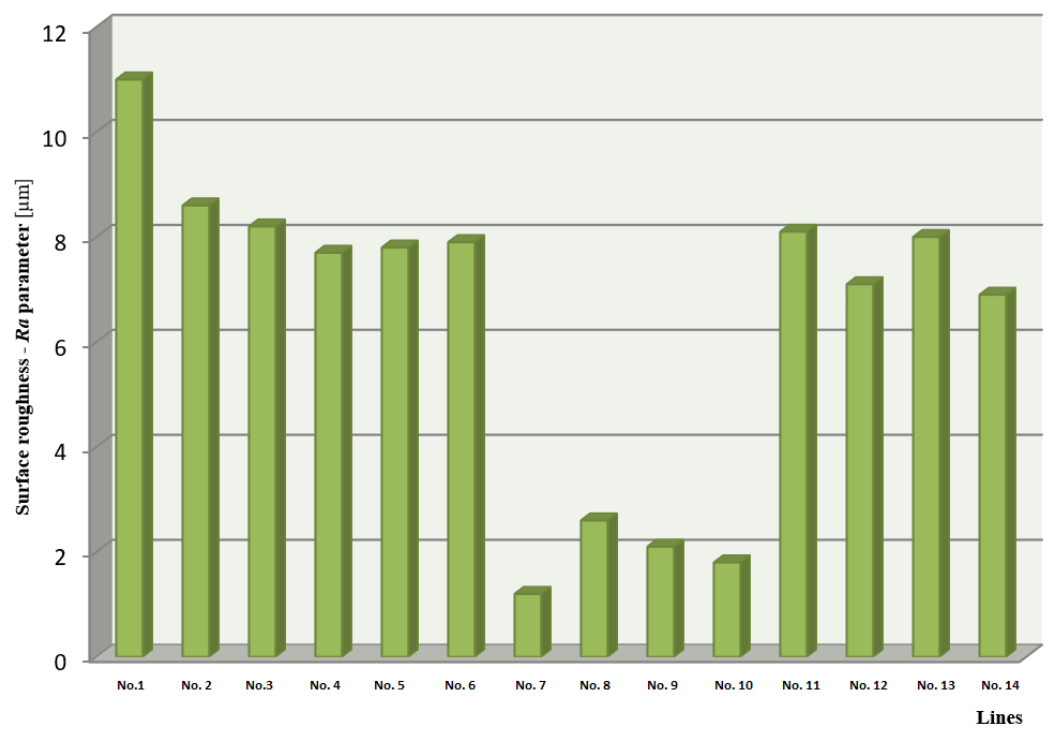

Figure 8. Graphical interpretation of surface roughness (X1 sample) - Ra parameter

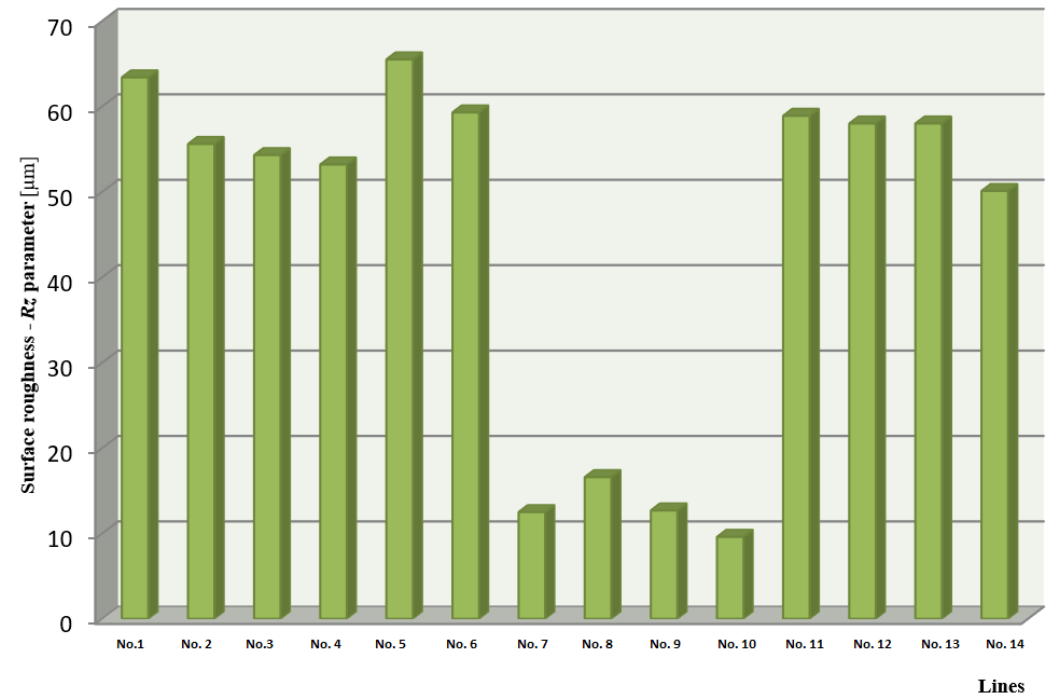

Figure 9. Graphical interpretation of surface roughness - Rz parameter

There are obviously significant differences between the parameters in each line. The lowest values of surface roughness parameters $\mathrm{Ra} / \mathrm{Rz}$ are evident for lines 7 - 10 (minimum value $\mathrm{Ra}=1.2 \mu \mathrm{m}-$ line $7, \mathrm{Rz}=$ $9.6 \mu \mathrm{m}$ - line 10). The maximum value of the surface roughness parameter $\mathrm{Ra}$ is recorded in line 1, the Rz parameter in line 5 (specifically $\mathrm{Ra}=11 \mu \mathrm{m} / \mathrm{Rz}=65.5 \mu \mathrm{m})$. Average values of parameters, maximum and minimum are recorded in Table 4. .

Table 4. Determined characteristics of parameters

\begin{tabular}{|l|c|}
\hline Determination of values & $\mathrm{Ra}[\mu \mathrm{m}] / \mathrm{Rz}[\mu \mathrm{m}]$ \\
\hline Minimum values & $1.2 / 9.6$ \\
\hline Maximum values & $11.0 / 65.5$ \\
\hline Average values & $6.35 / 44.85$ \\
\hline
\end{tabular}



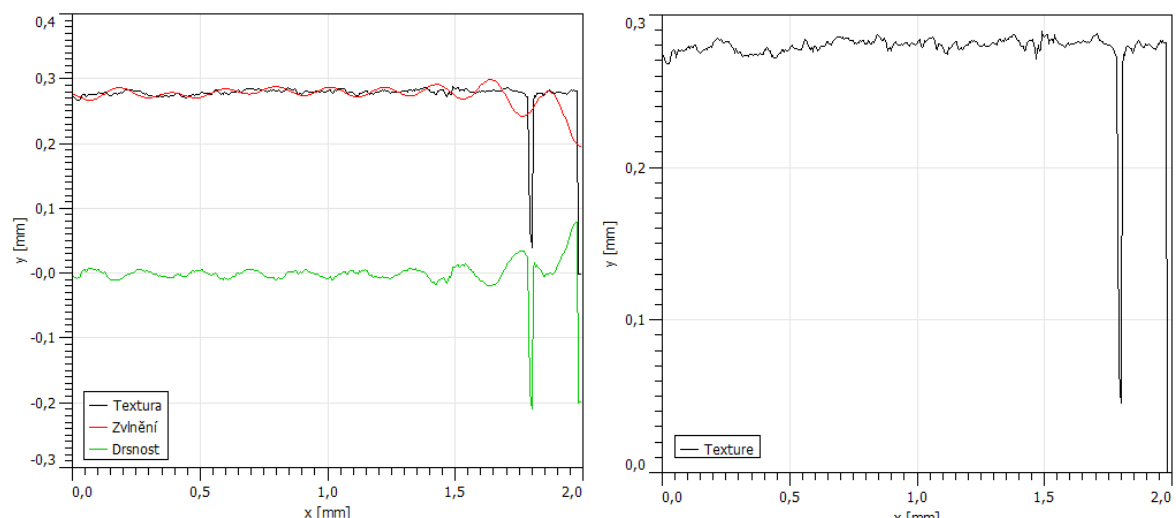

Figure 10. Graphical interpretation of profile (line 1)
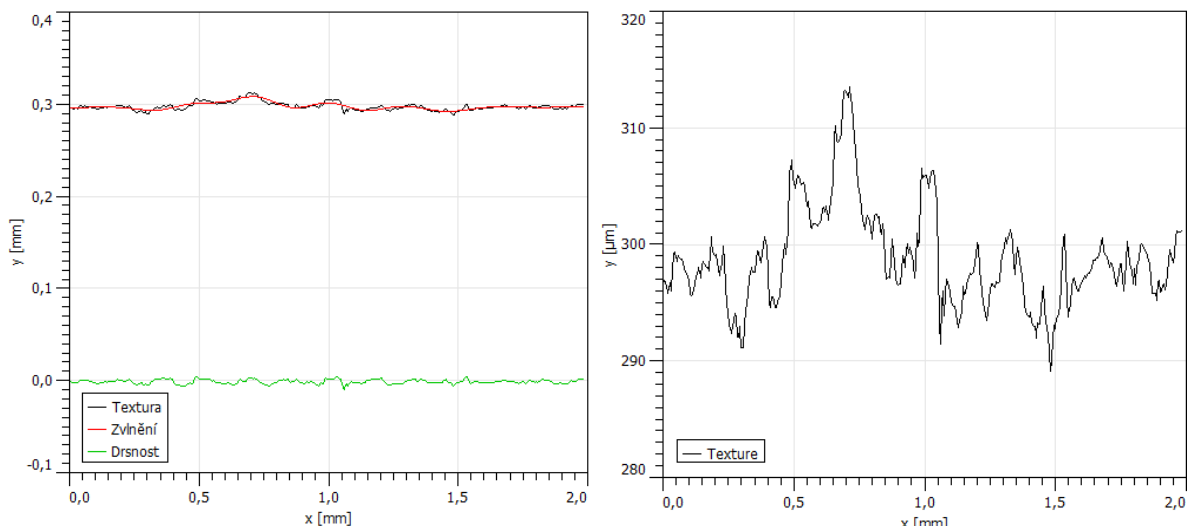

Figure 11. Graphical interpretation of profile (line 10)
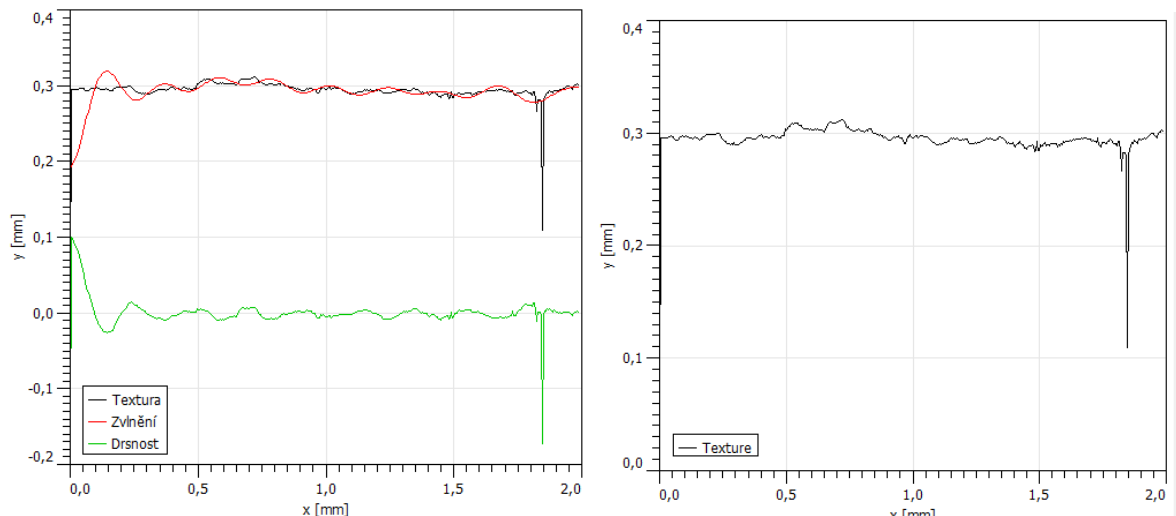

Figure 12. Graphical interpretation of profile (line 11) 

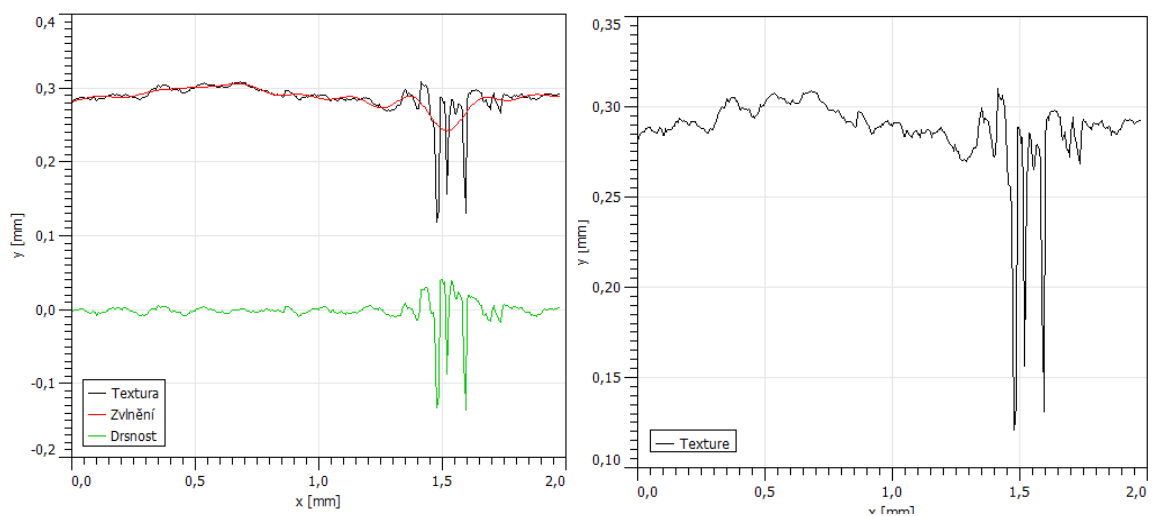

Figure 13. Graphical interpretation of profile (line 13)

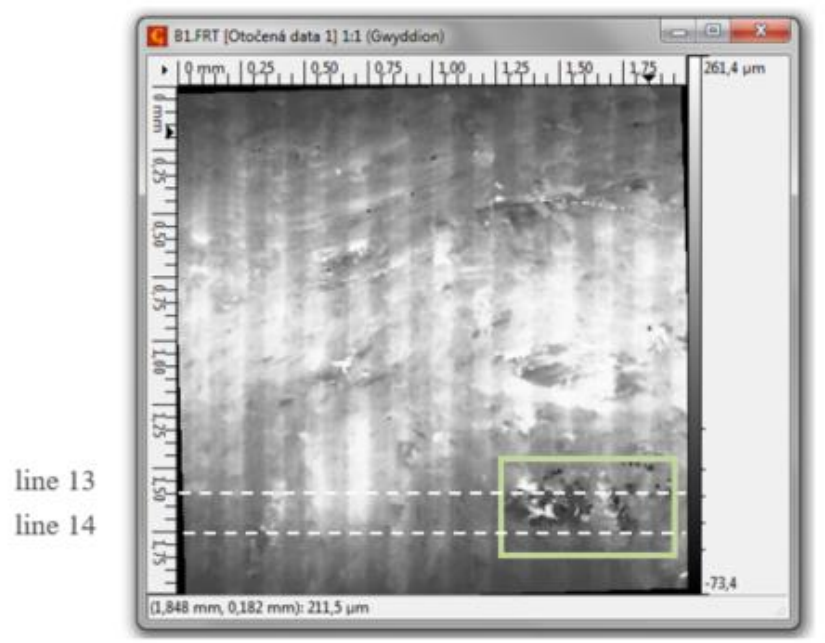

Figure 14. Scanned area (size: $2 \times 2 \mathrm{~mm}$ ) - highlighted area crossing line 13 and 14

The results presented in Figures 10-13 show the diversity of profiles for one sample $(2 \times 2$ $\mathrm{mm}$ ). The highlighted area (Fig. 13) is intersected by line 13 and partially captured also by line 14 (Fig. 14 - dark areas - a noncaptured cloud of points - significant depressions on the sample are likely to be torn chips after turning technology). The differences between the measured values of the surface roughness parameters as well as the visibly different profiles are caused by the material composition - plastic matrix + reinforcement in the form of chips (the material is not perfectly homogeneous).

\section{Conclusion}

The method of optical profilometry allows to observe the uneven surfaces of the examined samples, and by selecting a suitable program to evaluate/process the selected parameters. The surface roughness parameters $\mathrm{Ra} / \mathrm{Rz}$ (according to standard ISO 4287) were evaluated on the scanned area in fourteen lines. Experimental samples and their respective textures define its differences in surface profiles, which were caused by different mechanical characterization in the areas of the interaction between intimal raw particles ( that can be also monitored on the macroscopic level). 
Acknowledgment: This supported by research research was

grant KEGA
030TUKE-4/2018 and VEGA 1/0682/17.

\section{References:}

Buehlmann, U., Saloni, D., \& Lemaster, R. L. (2001, July). Wood Fiber-Plastic Composites: Machining and Surface Quality. Materiały konferencyjne 15th International Wood Machining Seminar Anaheim CA.

Duplák, J., Brezíková, K., Cep, R., Kuric, I., Ivanov, V., Petruska, O., \& Mrosková, L. (2017). Efficient machining of steel S355JR after the laser cutting-case study. In 2nd EAI International Conference on Management of Manufacturing Systems (p. 58). European Alliance for Innovation (EAI).

Guo, X. L., Liu, H. N., Gao, W., Cao, P. X., \& Guo, Y. (2010). Effects of spindle speed on surface qualities in WPC sawing. Applied Mechanics and Materials, 33, 487-491.

Hatala, M., Duplák, J., Dupláková, D., \& Botko, F. (2019). Effect of Traverse Speed on Surface Roughness Parameters after Laser Cutting of Non-alloy Structural Steel. TEM Journal, 8(2), 402.

Hutyrová, Z., Kušnerová, M., Harničárová, M., Valíček, J., Tozan, H., \& Mital, D. (2016). Evaluation of texture surface of composite material based on WPC after using machining technology. Advanced Science Letters, 22(3), 678-680.

Hutyrová, Z., Ščučka, J., Hloch, S., Hlaváček, P., \& Zeleňák, M. (2016). Turning of wood plastic composites by water jet and abrasive water jet. The International Journal of Advanced Manufacturing Technology, 84(5-8), 1615-1623.

Panda, A., Dyadyura, K., Valíček, J., Harničárová, M., Zajac, J., Modrák, V., ... \& Pavelek, Z. (2017). Manufacturing technology of composite materials - principles of modification of polymer composite materials technology based on polytetrafluoroethylene. Materials, 10(4), 377.

Somsakova, Z., Zajac, J., Michalik, P., \& Kasina, M. (2012). Machining of wood plastic composite (pilot experiment). Materiale plastice, 49(1), 55-57.

Valíček, J., Harničárová, M., Öchsner, A., Hutyrová, Z., Kušnerová, M., Tozan, H., ... \& Zajac, J. (2015). Quantifying the mechanical properties of materials and the process of elastic-plastic deformation under external stress on material. Materials, 8(11), 7401-7422.

Waltz, F. (1982). Machining wood and plastics with SYNDITE tools. Industrial Diamond Review, 42(493), 339-340.

Wei, W., Li, Y., Xue, T., Tao, S., Mei, C., Zhou, W., \& Wang, T. (2018). The research progress of machining mechanisms in milling wood-based materials. BioResources, 13(1), 2139-2149.

Wei, W. H., Xie, S. Y., Xue, T. M., Yao, F. Y., Xu, J. W., Liu, D. L., \& Wang, T. Y. (2016). High speed cutting characteristics and force measurement experimental platform of wood plastic composites. Key Engineering Materials, 693, 795-799.

Wilkowski, J., Borysiuk, P., Górski, J., \& Czarniak, P. (2013). Analysis of relative machinability indexes of wood particle boards bonded with waste thermoplastics. Drewno: prace naukowe, doniesienia, komunikaty, 190, 55-57.

Zelinka, J., Čepová, L., Gapiński, B., Čep, R., Mizera, O., \& Hrubý, R. (2019). The Effect of a Stylus Tip on Roundness Deviation with Different Roughness. Advances in Manufacturing II, $147-15$ 
Zuzana Mitalova

Technical University of Kosice, Faculty of

Manufacturing

Technologies with a seat in

Presov,

Presov,

Slovakia

zuzana.mitalova@tuke.sk

\section{Juliana Litecka}

University of Presov,

Faculty of Humanities and

Natural Science,

Ul. 17. Novembra 1,

Presov,

Slovakia

juliana.litecka@unipo.sk
Darina Duplakova

Technical University of

Kosice, Faculty of

Manufacturing

Technologies with a seat in

Presov,

Presov,

Slovakia

darina.duplakova@tuke.sk

\section{Velimir Dedic}

Faculty of Information

technology and engineering

- FITI,

Jurija Gagarina 149a,

Belgrade,

Serbia

velimir.dedic@fsom.edu.rs
Dusan Mital

Technical University of

Kosice, Faculty of

Manufacturing

Technologies with a seat in

Presov,

Presov,

Slovakia

dusan.mital@tuke.sk

\section{Enes Sukic}

Faculty of Information technology and engineering

- FITI,

Jurija Gagarina 149a,

Belgrade,

Serbia

enes.sukic@fiti.edu.rs 


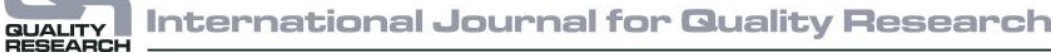

